\title{
Hydatid Cyct Disease with Extra Hepatic Localizations
}

\author{
Mehmet Kadir Bartın* \\ Department of General Surgery, Turkey
}

*Corresponding author: Mehmet Kadir Bartın General Surgery Specialist, Department of General Surgery, Van Educational and Research Hospital, Van, Turkey

\begin{tabular}{lll}
\hline ARTICLE INFO & & ABSTRACT \\
\cline { 1 - 1 } $\begin{array}{l}\text { Received: 幽July 16, } 2019 \\
\text { Published: }\end{array}$ & $\begin{array}{l}\text { Citation: Mehmet Kadir Bartın. Hydatid Cyct Disease with Extra Hepatic Localizations. Bi- } \\
\text { omed J Sci \& Tech Res 19(5)-2019. BJSTR. MS.ID.003367. }\end{array}$ \\
\hline
\end{tabular}

\section{Introduction}

Echinococus granulosus causes the echinococcosis also known as hydatid cyst disease. Hydatid cyst disease is a parasitic infection. This parasit is identified by Basch for the first time and defined as echinococus granulosus [1]. Hydatid cyst is presently a prevalent health problem in our country. Echinococus granulosus may indwell all the organs. But liver and lungs are affected usually. Especially; extrahepatic localization is rare. Animals consumed as nutrients, are parasit's intermediate host. The last host is canine genus. The echinococus larvas named as hexagons, are taken by gastrointestinal way. The embryos come to liver by the veins and to the other organs by the lenfatic way. In this article, hydatid cyst cases presenting with different clinical features and localized in ex-

\section{Methods}

Patients; with hydatid cysts who are operated in our hospital, between 2015 and 2018, were evaluated. 20 patients with hydatid cyst disease who has extra hepatic located cysts, were detected. Patients were evaluated in terms of; age, sex, location of the cyst, cyst size, diagnostic method, applied surgical method and recurrence. Chest radiography, ultrasonography (USG) and computerized tomography (CT) was performed for all patients before surgery. $1 / 320$ serum titres were accepted as positive for echinococcosis for indirect hemagglutination test (IHA) in our hospital. Liver located cases and echinococcus alveolaris cases were eleminated. trahepatic organs, are discussed.

\section{Results}

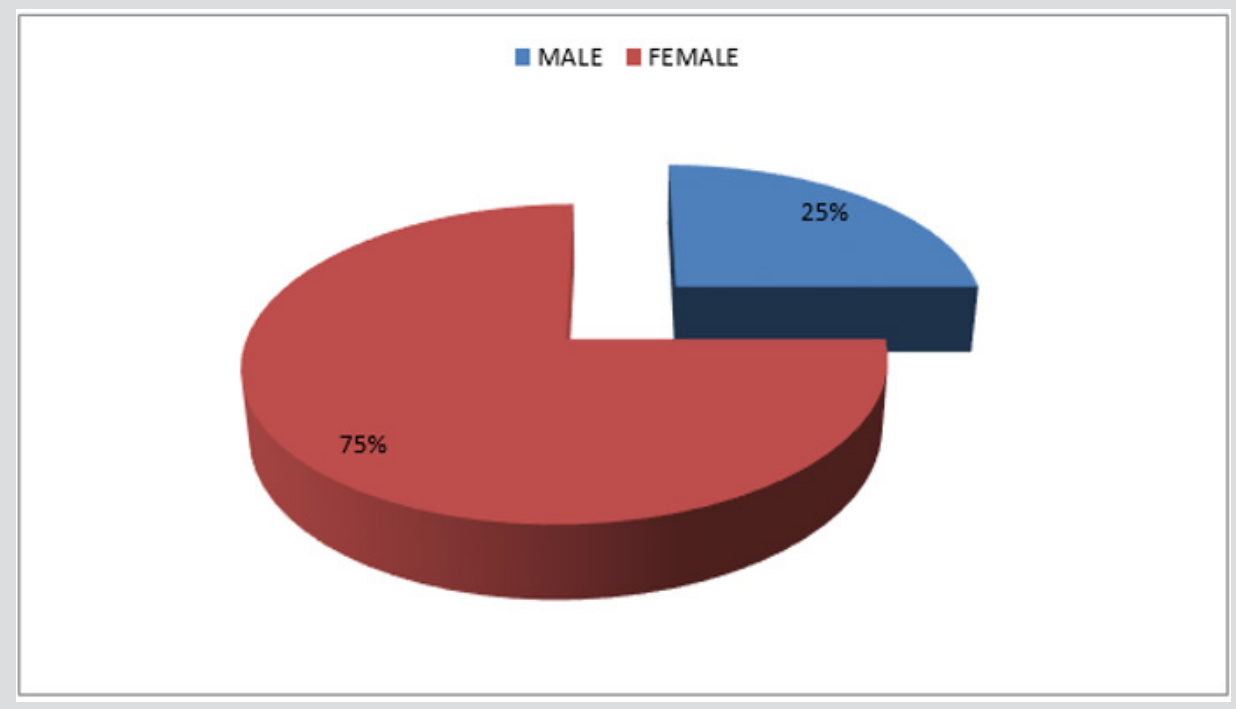

Figure 1: Gender distribution of the patients. 
$15(\% 75)$ patients were female and $5(\% 25)$ patients were male. The mean age among the patients were 34,5 (17y-63y) (Figure 1) 10 cycsts were localized in lungs ( 8 right lobe and 2 left lobe), 5 in spleen, 2 in peritoneal cavity ( 1 of them was in right inguinal hernia pouch), 1 in thyroid, 1 in left paravertebral muscles and 1 in gall bladder (Figure 2). The mean cyst size was calculated as $8.05 \mathrm{~cm}$ $(2 \mathrm{~cm}-22 \mathrm{~cm})$. Lung located cysts were diagnosed by chest graphy and CT, thyroid located cyst, 3 of spleen located cysts, peritoneal cavity located cysts and gall bladder located cyst were diagnosed by USG, (Figure 3) 2 of spleen located cysts and paravertebral muscle located cyst were diagnosed by CT (Figure 4). Total splenectomy was performed to spleen located cysts. Thyroid cyst was treated by bilateral total thyroidectomy. Lung cysts were treated by cyst wall resection (subtotal cystectomy). Total cystectomy was performed for the peritoneal cavity cysts and paravertebral muscle located cyst. Recurrence occurred in paravertebral muscle cyst and in 1 of lung cysts. And total cystectomy was performed for these cysts. No recurrence occured again. All the patients were administered postop $10 \mathrm{mg} / \mathrm{kg}$ albendazole. After four weeks of medical treatment, patients undergo USG control. There was no recurrence in this period (Table 1).

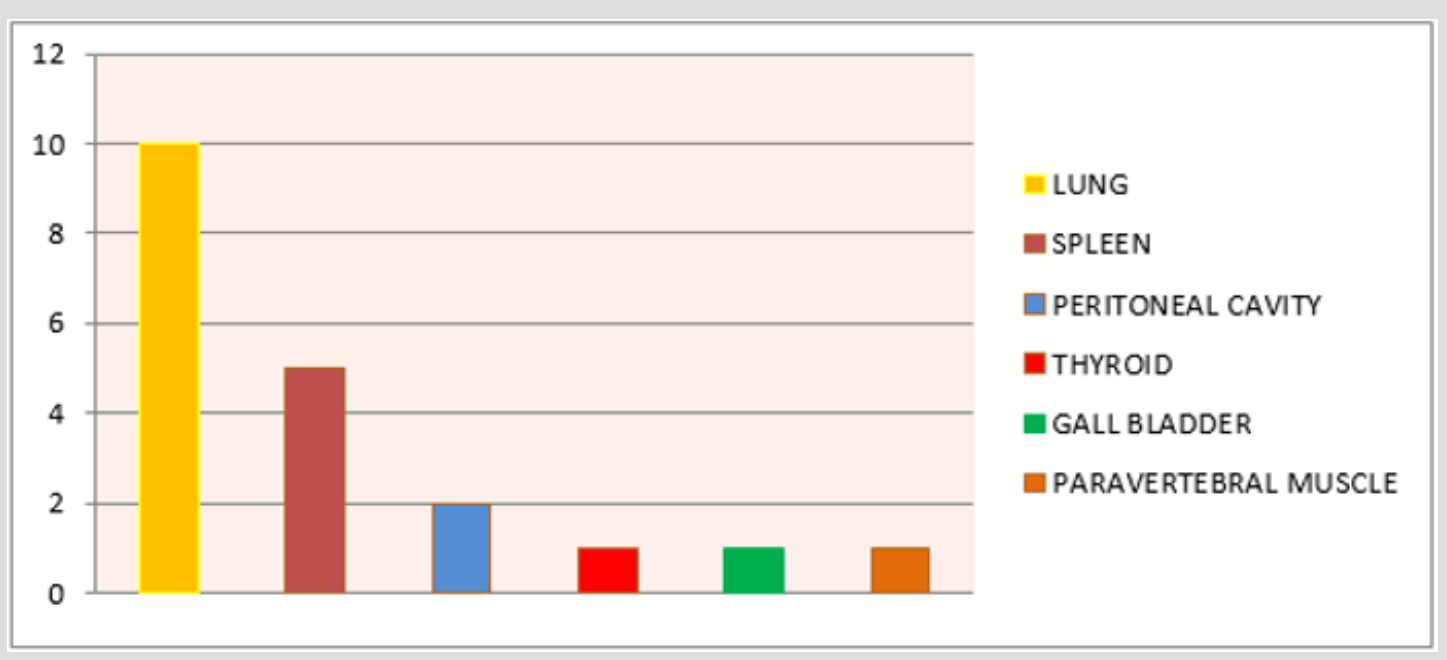

Figure 2: Localization of the cysts.

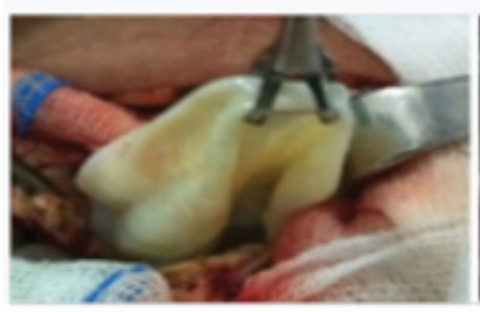

A

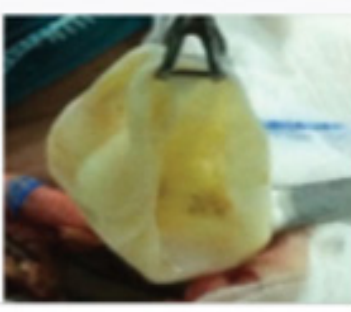

B

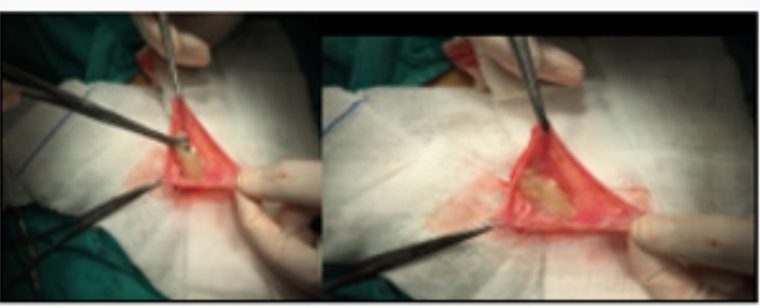

C

D

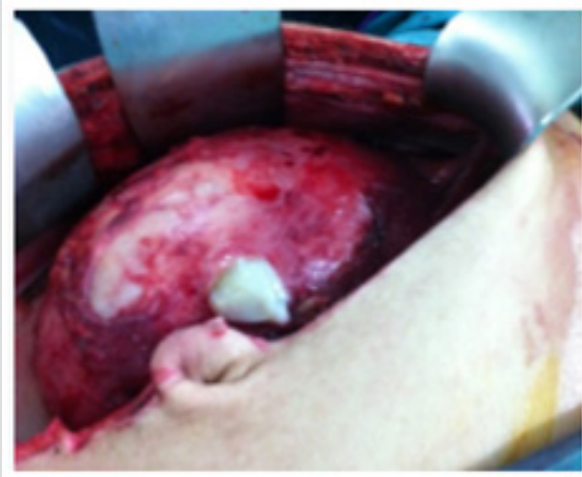

E

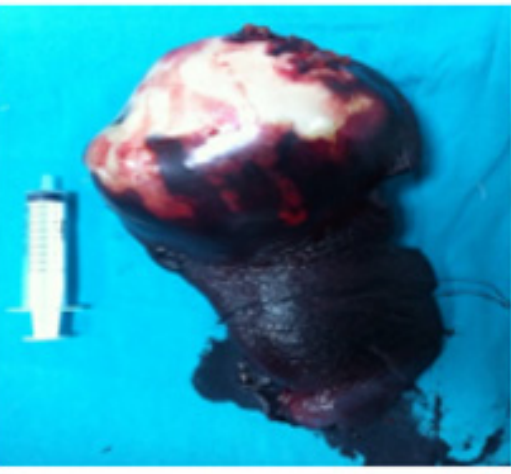

F

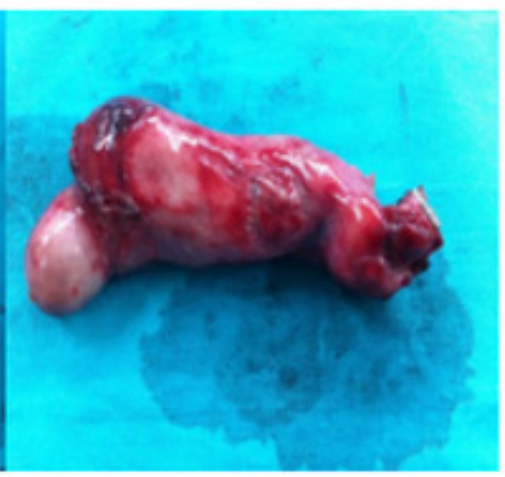

G

Figure 3: Peroperative photo examples of cysts; Thyroid (A,B)-Inguinal Hernia posh (C,D)-Peritoneal Cavity (E)-Spleen (F)Gall bladder (G). 


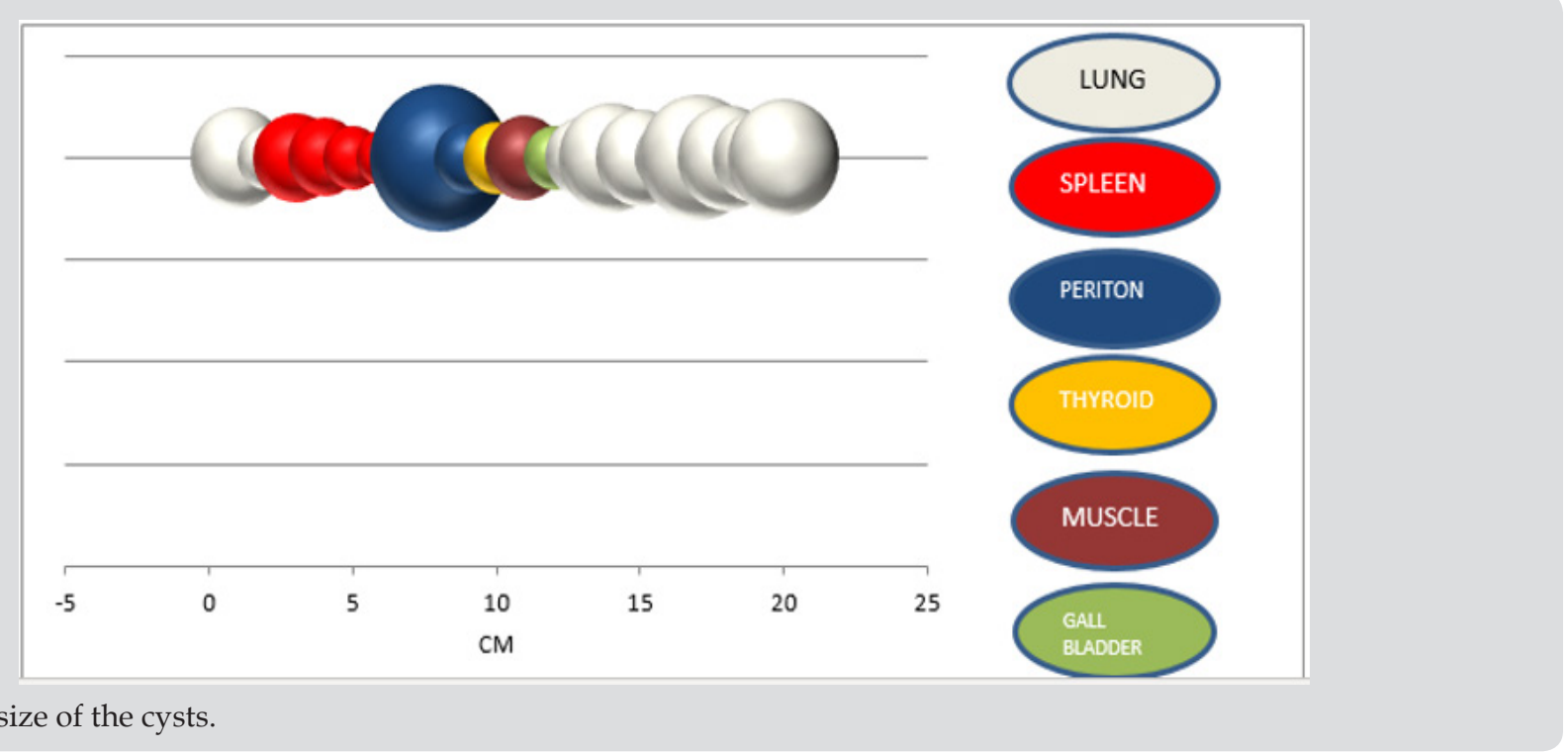

Figure 4: The size of the cysts.

Table 1: Demographic data \& Localization and the size of the cysts \& Diagnostic methods.

\begin{tabular}{|c|c|c|c|c|c|}
\hline NO & AGE & SEX & LOCALISATION & DIAGNOSTIC METHOD & SIZE OF THE CYST(CM) \\
\hline 1 & 17 & $\mathrm{~F}$ & LUNG & CT\&CHEST GRAPHY & 8 \\
\hline 2 & 22 & $\mathrm{~F}$ & LUNG & CT\&CHEST GRAPHY & 10 \\
\hline 3 & 21 & $\mathrm{~F}$ & LUNG & CT\&CHEST GRAPHY & 4 \\
\hline 4 & 54 & M & LUNG & CT\&CHEST GRAPHY & 6 \\
\hline 5 & 40 & M & LUNG & CT\&CHEST GRAPHY & 14 \\
\hline 6 & 19 & $\mathrm{~F}$ & LUNG & CT\&CHEST GRAPHY & 11 \\
\hline 7 & 63 & $\mathrm{~F}$ & LUNG & CT\&CHEST GRAPHY & 16 \\
\hline 8 & 41 & $\mathrm{~F}$ & LUNG & CT\&CHEST GRAPHY & 5 \\
\hline 9 & 32 & $\mathrm{M}$ & LUNG & CT\&CHEST GRAPHY & 9 \\
\hline 10 & 33 & $\mathrm{~F}$ & LUNG & CT\&CHEST GRAPHY & 12 \\
\hline 11 & 24 & M & SPLEEN & USG & 8 \\
\hline 12 & 25 & $\mathrm{~F}$ & SPLEEN & USG & 6 \\
\hline 13 & 30 & $\mathrm{~F}$ & SPLEEN & CT & 4 \\
\hline 14 & 19 & $\mathrm{~F}$ & SPLEEN & USG & 3 \\
\hline 15 & 28 & $\mathrm{~F}$ & SPLEEN & CT & 2 \\
\hline 16 & 59 & $\mathrm{~F}$ & PERITON & USG & 22 \\
\hline 17 & 55 & $\mathrm{~F}$ & PERITON & USG & 5 \\
\hline 18 & 49 & M & THYROID & USG & 5 \\
\hline 19 & 47 & $\mathrm{~F}$ & MUSCLE & CT & 7 \\
\hline 20 & 20 & $\mathrm{~F}$ & GALL BLADDER & USG & 4 \\
\hline
\end{tabular}

\section{Discussion}

Hydatid cyst disease is most commonly seen in the liver (\%70). But all organs and systems may be affected. This parasit may settle in lung, muscle, bone, kidney, brain, heart, prostate, pancreas. thyroid and spleen [2]. Isolated extrahepatic replacements are very rare [3]. In the literature it has been reported that; isolated hydatid cyst disease may settle; in spleen $\% 2.2$, in pancreas $\% 1.1$, in periton or pelvic area and mesocolon $\% 2.2$, in gall bladder $\% 0.6$, in surrenal glands $\% 0.6$ and rarer in other organs [4]. The results of our study is in accordance with the literature about the frequency. This disease has a lot of clinical symptoms according to the size, age and the replacement of the cysts. Abdominal pain and tenderness, hepatomegaly and abdominal palpable mass, hydatid trill may be seen [5]. Eosinophilia is found in $25 \%$ of patients and Weinberg complement fixation test (CFT) may be positive and diagnostic with clinical findings [6]. Also, indirect hemagglutination test (IHA) is used. In 1994; Lucahandri et al. operated 1275 patients for the hydatid cyst. They reported that; \%5-75 rate of this cysts may exhibit in extraordinary organs [7]. 
Gassias et al. reported that; extrahepatic localized hydatid cyst's rate is \%10 diagnosed by USG, CT and MRI [8]. Bartın et al. demonstrated that the imaging methods are more sensitive than serological tests especially in unusual cyst locations, and identification of germinative membranes or germinal vesicles while serological tests are negative should be assessed in favour of echinococcosis [9]. In our study most of the cases diagnosed by imaging techniques. Surgical treatment is the first and most important method for the hydatid cyst disease even with antihelminthics [10-12]. In surgical treatment; the affected organ can be removed totally or partially with the cysts. Parenchymal resection and simple cystectomy are the other applied surgical treatment method. The most common used surgical technique is total or subtotal pericystectomy $[13,14]$. In our study; total organ resections (splenectomy, total thyroidectomy, cholecystectomy) applied for the cysts located in spleen, thyroid and gall bladder. Subtotal cyst resections (pericystectomy) are made for the lung cysts. And total cystectomy applied for the cysts in peritoneal cavity and muscle localizated cyst.

Antihelminthics are the alternative treatment method for small and asymptomatic cysts [15]. Albendazole is an antihelmintic which is used frequently with the dose of $10 \mathrm{mg} / \mathrm{kg} /$ day [16]. In the studies of Horton and El-Mufti; the improvement rate is nearly $\% 50$ and $\% 90$ of recurrent cysts are in advanced stage and reported to be susceptible to albendazole treatment $[17,18]$. In our study one of the recurrent cysts is the old and big cyst $(16 \mathrm{~cm})$ in lung and the other recurrent cyst is paravertebral muscle localized cyst which is also old age. So, it is compatible with the literatüre that the size and age of the cyst affect recurrent ratio [19]. The recurrent ratio in our study is $2(\% 10)$ and in literature the recurrent ratio changes between \%3-26 [20]. After concomitant administration of surgical and medical treatment; it is reported that recurrence rate decreases [14]. In our study all petients have surgical and medical treatment together.

\section{Conclusion}

The diagnose of extrahepatic located hydatid cyst disease may be difficult. Serological tests may be misleading and imaging methods are more valuable for these cysts. The first treatment step is surgery, but also medical treatment should be added. It is important not to forget that the cyst size and the age of the cyst is important for the recurrence.

\section{Informed Consent}

Written informed consent was obtained from patient who participated in this study.

\section{Peer Review}

Externally peer reviewed.

\section{Conflict of Interest}

No conflict of interest was declared by the author.

\section{Financial Disclosure}

The author declared that this study has received no financial support.

\section{References}

1. Amir Jahed AK, Fardin R, Farzad A, Bakshandeh K (1975) Clinical echinococcosis. Ann Surg 182(5): 541-546.

2. Kushwaha JK, Sonkar AA, Verma AK, Pandey SK (2012) Primary disseminated extrahepatic abdominal hydatid cyst: a rare disease BMJ Case Reports.

3. Yazıcı P, Aydın U, Ersin S, Kaplan H (2007) Dalak yerleşimli kist hidatik: klinik çalıma. EAJM 37(1): 25-27.

4. Wani RA, Malik AA, Chowdri NA, Wani KA, Naqash SH, et al. (2005) Primary extrahepatic abdominal hydatidosis. Int J Surg 3(2): 125-127.

5. Mourmen M, El Alaqou ME, El Mansouri A, Mokhtari M, El Fares F, et al. (1991) Peritoneal echinococcosis. Diagnostic and therapeutic problems. Apropos34 cases Chirurgie 117(10): 854-859.

6. Danicic B, Mirkovic M, lic M (1989) 20 years' experience in the treatment of absominal echinococcosis (1966-1987) Acta Chir Jugosl 36: 579-582.

7. Luchandri Q Diella Q Chiavellati L, Sterpetti A, Meloni E, et al. (1994) Unusual location of hydatid cyst: Clinical and therapeutic aspects. G Chir 15(11): 529-537.

8. Gossios KJ, Kontoyiannis DS, Daskalogiannaki M (1997) Uncommon location of hydatid disease CT appearances. Eur Radiol 7(8): 1303-1308.

9. Bartın MK, Yllmaz EM, Tekeli AE (2015) A case of primary hydatid cyst in the thyroid gland Ulus Cerrahi Derg 31(2): 94-95.

10. Vara-Thorbeck C, Vara Thorbeck R (1986) Peritoneal echinococcosis Zentrabl Chir 11(16): 980-986.

11. Danicic B, Mirkovic M, lic M (1989) 20 years experience in the treatment of absominal echinococcosis (1966-1987). Acta Chir Jugosl 36(2): 579582 .

12. Cangiotti L, Muiesan P, Begni A, de Cesare V, Pouchè A, et al. (1994) Unusual location of hydatid disease; 18 years experience. G Chir 15(3): 83-86.

13. El Mansari O, Zentar A, Sair K, Bounaim A, Janati IM, et al. (2000) Peritoneal hydatid cysts. Apropos of 12 cases. Ann Chir 125(4): 353-357.

14. Loi A, mannu B, Montisci R, Pinna AD, Tallouru M, et al. (1991) Surgical treatment of hydatidosis. Ann Chir Gynecol 80(1): 59-64.

15. Prousalidis J, Tzardinoglou K, Katsohis C, Sgouradis L, Aletras H (1998) Uncomon sites of hydatid disease. World J Surg 22(1): 17-22.

16. Kalovidouris A, Gouliamos A, Demou L, Papavassiliou K, Vlachos L, et al. (1984) Postsurgical evaluation of hydatid diseasewith CT: Diagnostic pitfalls. J Comput Assist Tomogr 8(6): 1114-1149.

17. El Mufti M, Kamag A, brahin H, Taktuk S, Swaisi I, et al. (1993) Albendazole therapy of hydatid disease: 2-year follow up of 40 cases. Ann Trop Med Parasitol 87(3): 241-246.

18. Khiari A, Fabre JM, Domergue J, Beyrouti M (1995) Unusual location of hydatid cysts. Anal Gastroenterol Hepatol 31(5): 295-305.

19. Teggi A, Lastilla MG, De Rossa F (1993) Therapy of humanhydatid disease with mebendazole and albendazole. Antimicrob Agents Chemother 37(8): 1679-1684.

20. Smego RA, Sebanego P (2005) Treatment options for hepatic cystic echinococcosis. Int J Infect Dis 9: 69-76. 
ISSN: 2574-1241

DOI: 10.26717/BJSTR.2019.19.003367

Mehmet Kadir Bartın. Biomed J Sci \& Tech Res

CC (P) This work is licensed under Creative

Submission Link: https://biomedres.us/submit-manuscript.php

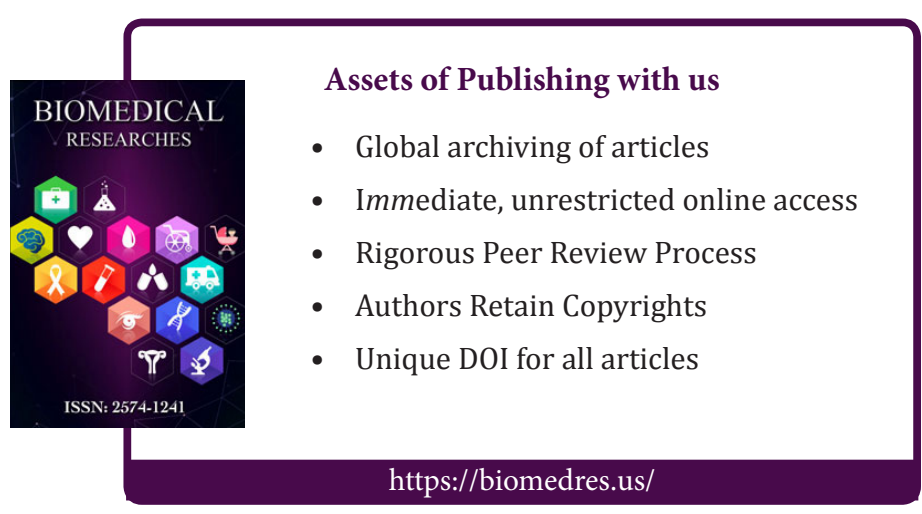

